\title{
PERCEPTION OF POSTGRADUATE FAMILY MEDICINE TRAINEES ABOUT THE OBJECTIVE STRUCTURED CLINICAL EXAMINATION (OSCE) ASSESSMENT METHOD
}

\author{
Abdul Jalil Khan ${ }^{1}$, Humera Adeeb ${ }^{2}$, Ihsan Ullah ${ }^{3}$, Brekhna Jamil ${ }^{4}$, Kashif Ali Samin ${ }^{1}$, Muhammad Jawad \\ ${ }^{1}$ Department of Family Medicine, Khyber Medical University Peshawar - Pakistan \\ ${ }^{2}$ Department of Community Medicine, Khyber Medical College Peshawar - Pakistan \\ ${ }^{3}$ Institute of Pathology and Diagnostic Medicine, Khyber Medical University Peshawar - Pakistan \\ ${ }^{4}$ Institute of Health Professions Education and Research, Khyber Medical University Peshawar - Pakistan
}

\begin{abstract}
Objectives: Assessment drives learning and improving the quality of assessment has a remarkable impact on the quality of learning. Objective Structured Clinical Examination is termed more reliable and valid as compared to conventional practical examination.
\end{abstract}

Objective: The objective of this study was to find the perception of postgraduate family medicine trainees about the OSCE assessment method and compare those having previous experience with those having no previous experience.

Material \& Mothods: This was a cross-section study conducted at the end of exit examination of diploma in family medicine at the Family Medicine Department, Khyber Medical University Peshawar. Data were collected on an eleven items questionnaire on a five-point Likert Scale. Study participants were categorized based on their previous experience of the OSCE, and were grouped into two categories. Data were analyzed by using Fisher's Exact test and a p-value of $\leq 0.05$ was considered statistically significant.

Results: Out of 60,56 candidates returned completed questionnaires. The response rate was $93.33 \%$ where the majority were males 52(92.9\%). Participants with experience of the OSCE were 22 (39.3\%) while 34 (60.7\%) were having no experience of the assessment method. There was a significant difference $(p=0.001)$ in the perception about the OSCE with the simulated patient than real patient, fairness and reliability of the OSCE, stress and length of the OSCE and reduction of bias in the OSCE. The perception about weightage to be given to the OSCE in any examination was significantly different $(p=0.004)$ between the two groups.

Conclusion: Participants of both groups (experienced vs non-experienced) agreed on some aspects of the OSCE. Their opinion differed about the fairness, validity and stress related to the OSCE assessment method. This difference is probably explained by the inadequacy of an experience to form an opinion.

Keywords: Conventional practical examination, Family medicine, OSCE.

This article may be cited as: Khan AJ, Adeeb H, Ullah I, Jamil B, Samin KA, Jawad M. Perception of Postgraduate Family Medicine Trainees about the Objective Structured Clinical Examination (OSCE) Assessment Method. J Med Sci 2021

July;29(3):74-78

\section{INTRODUCTION}

Assessments have a steering effect on learning in medicine and current notion is "assessment for learning" rather than "assessment of learning" 1,2. Students usually study that part of the course that is going to be assessed. Their learning usually depends on their thinking of the as-

\section{Correspondence}

Dr. Humera Adeeb

Department of Community Medicine, Khyber Medical

College Peshawar - Pakistan

Email: adeebhumera@yahoo.com

Cell: +92-335-9579928

Date received: $\quad 07-11-2020$

Date revised: $\quad 06-08-2021$

Date accepted: $08-08-2021$ sessment method ${ }^{3}$. Assessment must have both educational and formative role to help the students learn and develop practical skills. However, to keep specific standards and assurance of public, it is also necessary to have summative test of the doctors performance ${ }^{4}$. Inaccuracies in the knowledge judgement, practical skills and doctors attitude may pose some risk to the patient ${ }^{5}$. The effective and efficient healthcare delivery requires sound knowledge of the subject, practical skills, analytical skills, communication skills, counseling and evidence- and system-based care. All these skills require an assessment method that is comprehensive, robust and reliable to assess these required attributes ${ }^{6}$.

For a credible and reliable assessment in medi- 
Perception Of Postgraduate family Medicine Trainees About The Objective Structured Clinical Examination (Osce)...

cine, it is essential not only to assess clinical knowledge and skills but professionalism and empathy also. Improving assessment has a remarkable impact on the quality of learning. Over the last two decades the evaluation of clinical performance has evolved and structured methods of assessment like Objective Structured Clinical Examination (OSCE) were introduced. OSCE was introduced by Harden in 1979 and now is used as a most valid method of clinical competence assessment in most medical examinations ${ }^{8,9}$. OSCE can test a wide range of skills which reduces sampling errors and improves the reliability of examination ${ }^{9}$.

In the course of Diploma in Family Medicine, OSCE was introduced as form of summative assessment. In Pakistan students and trainees are more familiar with the traditional forms of clinical assessment like long case and short cases during their course of study and training. OSCE was introduced to overcome the unreliability and lack of standardization in long case ${ }^{5,9}$.

The problems with traditional short cases and long cases are that performance depends on candidate's presentation. It makes it an assessment at "knows how" rather than "shows how" so not as reliable and authentic for clinical competence assessment. Only one long case and three or four short cases are used so only limited clinical skills can be assessed ${ }^{10}$.

In the diploma course, the expected level of skills was decided to at least at "shows how" level of the Millar's pyramid. According to Miller the traditional assessment of medical students was much focused on testing their knowledge and assessment did not reflect on how they would behave in a real-life workplace ${ }^{11,12}$.

Despite the facts about the unreliability of their traditional format of assessment, there may still be some anxiety to try a different mode of assessment they have never used before. Students who have been previously exposed to OSCE, preferred OSCE as method of assessment for clinical competence as compared to traditional clinical examination ${ }^{13}$. The objective of this study was to compare if comprehensive OSCE assessment, is as useful and reliable for assessment of Diploma Family Medicine students who are not exposed vs those exposed to this format of examination during their undergraduate and postgraduate training. The intention of using OSCE is to test their knowledge, attitudes, and skills to reach a summative decision to allow them to be fit to practice as independent family physicians.

\section{MATERIAL AND METHODS}

This was a cross-section analytical study conducted at Institute of Public Health and Social Sciences, Department of Family Medicine, Khyber Medical University Peshawar. Ethical approval was sought from the institute ethical review board. The study was conducted in 2019 and 2020 at the end of exit examination of Diploma in Family Medicine.

The diploma in Family Medicine is one year program with six modules and five mandatory clinical rotations. There is an OSCE examination at the of each module. There is an exit examination at the end of all modules. There are 12 stations, covering wide range of psychomotor and affective skills from the curriculum. Time allotted to each OSCE station was 15 minutes with 1 minute transition time between stations. Performance at each OSCE station was scored according to the checklist for that OSCE with items covering key skills for that station. Range of items on check list was between 10 and 20 .

A questionnaire comprising of 11 questions was developed based on constructs identified from the literature and was expert validated to eliminate or rephrase ambiguous questions. The questionnaire evaluated perception of the recently completed OSCE using a 5-point Likert scale with strongly agree (score of 1 ) at one end and strongly disagree (score of 5) at the other end.

The total population census was carried out to avoid loss of information because of small sample size. The participants were asked to complete a self-administered questionnaire after seeking informed written consent. The 56 out of 60 participants completed the questionnaire. Response rate was $93.33 \%$.

Data was analysed in Stastical Package for Social Sciences (SPSS) version 24. Age was calculated as mean and categorical variables; gender, years of education, duration in clinical practice, qualification, previous exposure to OSCE and formal training in the past were calculated as frequency and percentages. Five-point Likert scale was collapsed into 3 points scale (agree/strongly agree, neutral and disagree/strongly disagree) for the purpose of analysis. The response to 11 items on Likert scale was calculated as frequencies on each point for an item. Each item was compared by Fisher's Exact Test according to whether candidates had experience of being evaluated by OSCEs in the past or not. The Fisher Exact test was used for $2 \times 3$ contingency tables. This method was preferred to calculate $p$ value for a small sample size and some cells having frequency less than five ${ }^{14}$. Results were displayed in tables. P-value of $\leq 0.05$ was considered significant.

\section{RESULTS}

The total 56 participants were dominated by males 52(92.9\%). Mean age of study participants was 35.07 years. The participants with basic medical qualification like MBBS/MD were in majority $42(75 \%)$. The participants with postgraduate qualification were $16(28.6 \%)$. Half of the participants were currently involved in clinical practice and out of this28 (50\%), $16(28.24 \%)$ in clinical practice for seven or more years. The participant who had received formal training in clinical medicine constituted $8(14.3 \%)$, 
Perception Of Postgraduate Family Medicine Trainees About The Objective Structured Clinical Examination (Osce)...

Table 1: Descriptive statistics of the study participants

\begin{tabular}{|c|c|c|c|c|}
\hline Gender & Male & Female & & \\
\hline & $52(92.9 \%)$ & $4(7.1 \%)$ & & \\
\hline \multirow[t]{2}{*}{ Age (years) } & Min & Max & Mean & SD \\
\hline & 28 & 43 & 35.07 & 4.29 \\
\hline \multirow[t]{2}{*}{ Years of education } & 16years & 18years & & \\
\hline & $42(75 \%)$ & $14(25 \%)$ & & \\
\hline \multirow[t]{2}{*}{ Qualification of Participants } & MBBS/MD & MCPS & MPH & MPhil \\
\hline & $40(71.4 \%)$ & $2(3.6 \%)$ & $12(21.14 \%)$ & 2 (3.6\%) \\
\hline \multirow[t]{2}{*}{ Currently in clinical practice } & Yes & No & & \\
\hline & $28(50 \%)$ & $28(50 \%)$ & & \\
\hline \multirow{2}{*}{$\begin{array}{l}\text { Duration of clinical practice of } \\
28 \text { participants }\end{array}$} & $<7$ years & $\geq 7$ years & & \\
\hline & $12(20.7 \%)$ & $16(28.24 \%)$ & & \\
\hline \multirow{2}{*}{$\begin{array}{l}\text { Exposed to OSCE previously } \\
\text { over course of education }\end{array}$} & Yes & No & & \\
\hline & $22(39.3 \%)$ & $34(60.7 \%)$ & & \\
\hline \multirow{2}{*}{$\begin{array}{l}\text { Formal training received } \\
\text { before }\end{array}$} & Yes & No & & \\
\hline & $8(14.3 \%)$ & 48 (85.7\%) & & \\
\hline
\end{tabular}

Table 2: Likert scale questionnaire and data analysis by Fisher Exact Test

\begin{tabular}{|c|c|c|c|c|c|c|c|}
\hline & Question & $\begin{array}{c}\text { Expo- } \\
\text { sure } \\
\text { to OSCE }\end{array}$ & SA/A & $\mathbf{N}$ & DA/SDA & $\begin{array}{c}\text { EET } \\
\text { p-value }\end{array}$ & $\begin{array}{l}\text { Test statis- } \\
\text { tics }\end{array}$ \\
\hline \multirow[t]{2}{*}{1} & \multirow[t]{2}{*}{ OCSE with SP better than RP in ward } & Yes & $20(90.90 \%)$ & $0(0 \%)$ & $2(9.10 \%)$ & \multirow[t]{2}{*}{0.001} & \multirow[t]{2}{*}{16.92} \\
\hline & & No & $14(41.17 \%)$ & $10(29.41 \%)$ & $10(29.41 \%)$ & & \\
\hline \multirow[t]{2}{*}{2} & \multirow{2}{*}{$\begin{array}{l}\text { OSCE is fair and reliable as compared to } \\
\text { CPE (viva, long case, short case) }\end{array}$} & Yes & $20(90.90 \%)$ & $0(0 \%)$ & $2(9.10 \%)$ & \multirow[t]{2}{*}{0.001} & \multirow[t]{2}{*}{17.39} \\
\hline & & No & $20(58.82 \%)$ & $14(41.17 \%)$ & $0(0 \%)$ & & \\
\hline \multirow[t]{2}{*}{3} & \multirow{2}{*}{$\begin{array}{l}\text { OSCE covers a wide range of knowledge } \\
\text { and skills }\end{array}$} & Yes & $20(90.90 \%)$ & $2(9.10 \%)$ & $0(0 \%)$ & \multirow[t]{2}{*}{0.455} & \multirow[t]{2}{*}{1.44} \\
\hline & & No & $28(82.35 \%)$ & $6(17.64 \%)$ & $0(0 \%)$ & & \\
\hline \multirow[t]{2}{*}{4} & \multirow{2}{*}{$\begin{array}{c}\text { OSCE is fair to mark performance scores for } \\
\text { examiner }\end{array}$} & Yes & $12(54.54 \%)$ & $10(29.41 \%)$ & $0(0 \%)$ & \multirow[t]{2}{*}{0.782} & \multirow[t]{2}{*}{6.12} \\
\hline & & No & $20(58.82 \%)$ & $14(41.17 \%)$ & $0(0 \%)$ & & \\
\hline \multirow[t]{2}{*}{5} & \multirow{2}{*}{$\begin{array}{l}\text { Time allocated to each OSCE station is } \\
\text { adequate }\end{array}$} & Yes & $18(81.81 \%)$ & $2(9.09 \%)$ & $2(9.09 \%)$ & \multirow[t]{2}{*}{0.151} & \multirow[t]{2}{*}{20.13} \\
\hline & & No & $20(58.82 \%)$ & $4(11.76 \%)$ & $10(29.41 \%)$ & & \\
\hline \multirow[t]{2}{*}{6} & \multirow[t]{2}{*}{ OSCE is more stressful as compared to CPE } & Yes & $16(72.72 \%)$ & $0(0 \%)$ & $6(27.27 \%)$ & \multirow[t]{2}{*}{0.001} & \multirow[t]{2}{*}{22.46} \\
\hline & & No & $10(29.41 \%)$ & $16(47.05 \%)$ & 8 (23.52\%) & & \\
\hline \multirow[t]{2}{*}{7} & \multirow[t]{2}{*}{ OSCE is lengthy as compared to CPE } & Yes & $10(45.45 \%)$ & $0(0 \%)$ & $12(54.54 \%)$ & \multirow[t]{2}{*}{0.001} & \multirow[t]{2}{*}{23.98} \\
\hline & & No & $4(11.7 \%)$ & $18(52.94 \%)$ & $12(35.29 \%)$ & & \\
\hline \multirow[t]{2}{*}{8} & \multirow{2}{*}{$\begin{array}{l}\text { OSCE is useful to assess psychomotor } \\
\text { domain }\end{array}$} & Yes & $18(81.81 \%)$ & $4(18.18 \%)$ & $0(0 \%)$ & \multirow[t]{2}{*}{0.845} & \multirow[t]{2}{*}{0.62} \\
\hline & & No & $28(82.35 \%)$ & $6(17.64 \%)$ & $0(0 \%)$ & & \\
\hline \multirow[t]{2}{*}{9} & \multirow{2}{*}{$\begin{array}{l}\text { OSCE reduces bias by examiner as com- } \\
\text { pared to CPE }\end{array}$} & Yes & $16(72.72 \%)$ & $6(27.27 \%)$ & $0(0 \%)$ & 1.00 & 14.44 \\
\hline & & No & $12(35.29 \%)$ & $16(47.05 \%)$ & $6(17.64 \%)$ & & \\
\hline 10 & Adequate weightage should be given to & Yes & $22(100 \%)$ & $0(0 \%)$ & $0(0 \%)$ & 0.004 & 13.90 \\
\hline & & No & $24(70.58 \%)$ & $10(29.41 \%)$ & 0 & & \\
\hline 11 & OSCE should be continued as evaluation & Yes & $20(90.90 \%)$ & $2(9.10 \%)$ & $0(0 \%)$ & 0.285 & 2.12 \\
\hline & & No & $26(76.47 \%)$ & $8(23.52 \%)$ & $0(0 \%)$ & & \\
\hline
\end{tabular}

Note: SA (Strongly agree), A(Agree), N (Neutral), DA (Disagree), SDA (Strongly disagree), SP (simulated patient), RP (Real patient), CPE (Conventional practical examination) FET (Fisher's Exact Test),

MEC (Minimum expected count in cell) 
Perception Of Postgraduate Family Medicine Trainees About The Objective Structured Clinical Examination (Osce)...

irrespective of whether the training resulted in successful completion of postgraduate degree or not. The participants who had experience of being evaluated by OSCE, whether in graduate school or post-graduation constituted $22(39.3 \%)$ as opposed to $34(60.7 \%)$ who only had experience of conventional clinical examination in the form of short and long cases (Table-1).

The response to question whether OSCE with simulated patient (SP) is better than real patient (RP), demonstrated significant difference with a $p$-value of 0.001 . The participants with experience of OSCE in the past were more in agreement with statement than those with no exposure to OSCE previously. Similar differences ( $p=$ 0.001 ) were seen in comparing fairness and reliability of OSCE, stress of OSCE, reduction of bias in OSCE vs Conventional Practical Examination (CPE). Opinion regarding weightage to be given to OSCE in any examination was significantly different $(p=0.004)$ between two groups (Table-2).

\section{DISCUSSION}

The OSCE method of assessment is a recognized and commonly used tool in postgraduate medical education ${ }^{15}$. The aim of the study was to know the opinion of those who have not experienced OSCE in their undergraduate education and compare it with those who have had such experience. This feedback will help guide in successful implementation of OSCE in Diploma course of Family Medicine ${ }^{16,17}$. Keeping in view the $93.33 \%$ response rate, bias is unlikely thus giving strength to this study.

The both groups participants agreed on that OSCE is suitable for assessing wide range of knowledge and skills, specially psychomotor skills as supported by literature ${ }^{17,18}$. Both the groups also agreed that OSCE is easy to score for examiner, reduces bias by examiner and each OSCE station gets sufficient time for the task assigned $^{18}$. They agreed on OSCE being part of any evaluation programme in clinical medicine. Similar opinions were expressed by Pharmacy students and undergraduate students ${ }^{18,19-21}$

As compared to undergraduate students who took OSCE in Family Medicine and had no experience of OSCE before, gave positive response to majority of the aspects of OSCE ${ }^{17}$. In contrast to undergraduate students in Family Medicine, participants differed on the opinion that OSCE is better with simulated patient, fair and reliable. Majority of literature has reported otherwise in regard to fairness and reliability of OSCE ${ }^{17,18,22-24}$. These differing opinions might be explained by the fact that one experience of OSCE might be inadequate to form an opinion about these aspects of OSCE ${ }^{17}$.

The group with no prior experience of OSCE had significantly different opinion regarding weightage to be given to OSCE in any examination, in alignment with their doubts about its fairness and reliability. The group with prior OSCE exposure stated that OSCE examination takes more time as compared to CPE.

The difference in opinion was also observed regarding stress caused by OSCE. Surprisingly the group with no prior experience of OSCE termed it less stressful as compared to CPE. This might be explained partly by the fact that it was their first experience and they were briefed about the process of OSCE before examination, that might not be there in CPE ${ }^{17}$. The more stress expressed by participants with past exposure to OSCE may be attributed to their knowledge of objective and standardized nature of OSCE and the ability of OSCE to assess competencies other than as assessed by CPE. This aspect of OSCE needs good practice and may be the reason of stress among participants ${ }^{18}$. The test anxiety and stress is higher with OSCE as compared to other forms of assessment but has no or minimal influence of performance ${ }^{25}$. Providing training to all those involved and make them aware of any potential problems will make the OSCE run smoother, and students will adopt it quickly easier.

\section{CONCLUSION}

Participants of both groups reported OSCE as a positive experience that provide an opportunity to practice real life scenarios ${ }^{21}$. The differences in opinion between two groups regarding fairness, validity and stress related to OSCE, is probably explained by inadequacy of one experience to form opinion.

\section{LIMITATIONS}

Small number of female candidates in the study and study could not explore the effect of gender and personality on scoring OSCE assessment. This was a single centre study and involved participants of one speciality thus limiting generalization.

\section{RECOMMENDATIONS}

The In-depth qualitative exploration of doubts regarding fairness, reliability of OSCE and less stress as compared to CPE, by participants with no prior experience of OSCE need further exploration.

\section{ACKNOWLEDGEMENT}

The authors acknowledge participation of trainees of Diploma in Family Medicine for being part of this study.

\section{REFERENCES}

1. Hanson JL, Wallace CM, Bannister SL. Assessment for Learning: How to Assess Your Learners' Performance in the Clinical Environment. Pediatrics [Internet] [Internet]. 2020 [cited 2021 May 5]; 145(3):[e20193966 p.].

2. Norcini J, Burch V. Workplace-based assessment as an educational tool: AMEE Guide No. 31. Med Teach. 
Perception Of Postgraduate Family Medicine Trainees About The Objective Structured Clinical Examination (Osce)...

2007;29(9):855-71.

3. Preston R, Gratani M, Owens K, Roche P, Zimanyi M, Malau-Aduli B. Exploring the Impact of Assessment on Medical Students' Learning. Assess Eval High Educ. 2020;45(1):109-24.

4. Esler WK, Dziuban CD. Criterion referenced test: Some advantages and disadvantages for science instruction. Sci Educ. 1974;58(2):171-4.

5. Ponnamperuma GG, Karunathilake IM, McAleer S, Davis $\mathrm{MH}$. The long case and its modifications: a literature review. Med Educ. 2009;43(10):936-41.

6. Tabish S. Assessment methods in medical education. Int J Health Sci. 2008;2(2):3-7.

7. Ferris H, Flynn D. Assessment in Medical Education; What Are We Trying to Achieve? Int J High Educ. 2015;4(2):139-44.

8. Harden RM, Gleeson FA. Assessment of clinical competence using an objective structured clinical examination (OSCE). Med Educ. 1979;13(1):41-54.

9. Newble D. Techniques for measuring clinical competence: objective structured clinical examinations. Med Educ. 2004;38(2):199-203.

10. Wass V, Van der Vleuten C, Shatzer J, Jones R. Assessment of clinical competence. Lancet. 2001;357(9260):945-9.

11. Miller GE. The assessment of clinical skills/competence/ performance. Acad Med. 1990;65(9 Suppl):S63-7.

12. Witheridge A, Ferns G, Scott-Smith W. Revisiting Miller's pyramid in medical education: the gap between traditional assessment and diagnostic reasoning. Int $\mathrm{J}$ Med Educ. 2019;10:191-2.

13. Ameh N, Abdul M, Adesiyun A, Avidime S. Objective structured clinical examination vs traditional clinical examination: An evaluation of students' perception and preference in a Nigerian medical school. Niger Med J. 2014;55(4):310-3.

14. Bind MAC, Rubin DB. When possible, report a Fisher-exact \&lt;em\&gt;P\&lt;/em\&gt; value and display its underlying null randomization distribution. Proc Nati Acad Sci [Internet] [Internet]. 2020 [cited 2021 May 1]; 117(32):[19151e p.].

15. Zayyan M. Objective structured clinical examination: the assessment of choice. Oman Med J. 2011;26(4):219-22.

16. Khursheed I, Usman Y, Usman J. Students' feedback of objectively structured clinical examination: a private medical college experience. J Pak Med Assoc. 2007;57:148-50.

17. Raheel H, Naeem N. Assessing the Objective Structured Clinical Examination: Saudi family medicine undergraduate medical students' perceptions of the tool. J Pak Med Assoc. 2013;63(10):1281-4.

18. Khan A, Ayub M, Shah Z. An Audit of the Medical Students' Perceptions regarding Objective Structured Clinical Examination. Educ Res Int. 2016(1):4806398.
19. Larsen T, Jeppe-Jensen D. The introduction and perception of an OSCE with an element of self- and peer-assessment. Eur J Dent Educ. 2008;12(1):2-7.

20. Awaisu A, Mohamed MHN, Al-Efan QAM. Perception of pharmacy students in Malaysia on the use of objective structured clinical examinations to evaluate competence. Am J Pharm Educ [Internet]. 2007 [cited 2021 Apr 29]; 71(6):[118 p.].

21. Al-Haqan A, Al-Taweel D, Koshy S, Alghanem S. Evolving to Objective Structured Clinical Exams (OSCE): Transitional experience in an undergraduate pharmacy program in Kuwait. Saudi Pharm J. 2021;29(1):104-13.

22. Al-Naami MY. Reliability, validity, and feasibility of the Objective Structured Clinical Examination in assessing clinical skills of final year surgical clerkship. Saudi Med J. 2008;29(12):1802-7.

23. Skrzypek A, Szeliga M, Stalmach-Przygoda A, Górski S, Kowalska B, Kocurek A, et al. The Objective Structured Clinical Examination (OSCE) from the perspective of 3rd year's medical students - a pilot study. Folia Med Cracov. 2017;57(3):67-75.

24. Alsaid AH, Al-Sheikh M. Student and Faculty Perception of Objective Structured Clinical Examination: A Teaching Hospital Experience. Saudi J Med Sci. 2017;5(1):49-55.

25. Martin RD, Naziruddin Z. Systematic review of student anxiety and performance during objective structured clinical examinations. Currents in Pharmacy Teaching and Learning. 2020;12(12):1491-7.

CONFLICT OF INTEREST: Authors declare no conflict of interest

GRANT SUPPORT AND FINANCIAL DISCLOSURE: NIL

\section{AUTHOR'S CONTRIBUTION}

Following authors have made substantial contributions to the manuscript as under

Khan AJ: $\quad$ Main idea, data collection and manuscript writing

Adeeb H: Data collection, statistical analysis and manuscript writing

Ullah I: $\quad$ Literature review, Methodology, Manu script writing and critical review

Jamil B: $\quad$ Manuscript writing, Critical expert review and corrections

Samin KA: Manuscript writing, discussion and Critical review

Jawad M: Data collection, Manuscript writing, intro duction and references

Authors agree to be accountable for all aspects of the work in ensuring that questions related to the accuracy or integrity of any part of the work are appropriately investigated and resolved. 